\title{
Além da Forma-Movimento: Compilações do Movimento dos Pequenos Agricultores
}

\author{
Priscila Delgado de Carvalho*
}

\section{RESUMO}

Criado em meados da década de 1990, o Movimento dos Pequenos Agricultores foi inicialmente conhecido por suas demandas por crédito e por habitação rural. Ao longo dos anos, o MPA propôs também debates sobre o campesinato no Brasil, formulou ou ressignificou conceitos como alimergia e sistemas camponeses de produção, engajou-se em debates sobre políticas públicas, criou cooperativas e estruturou um Plano Camponês que orienta sua ação. O artigo reúne elementos da trajetória do MPA argumentando que a forma-movimento é sua primeira face visível, mas o MPA também construiu outros modos de compilar. Entre eles, a produção de conceitos em estreito diálogo com a academia e com debates de origem transnacional e a estruturação de projetos produtivos.

Palavras-chaves: Movimento social; Camponeses; Soberania alimentar.

* Pesquisadora em estágio pós-doutoral no Instituto Nacional de Ciência e Tecnologia (INCT) Democracia e Democratização da Comunicação. Doutora em Ciência Política pela Universidade Federal de Minas Gerais e mestra pela Universidade de Brasília, graduou-se em Comunicação Social pela Universidade de São Paulo. 


\begin{abstract}
BEYOND MOVEMENT-FORM: COMPILATIONS OF THE SMALL FARMERS MOVEMENT
\end{abstract}

Created in the mid-1990s, the Small Farmers Movement was initially known for its demands for credit and rural housing. Over the years, MPA has also proposed debates on the peasantry, formulated or recreated concepts such as alimergia and peasant production systems, engaged in public policy debates, created cooperatives and structured a Peasant Plan that guides its activists' action. The article brings together elements of MPA's trajectory arguing that the movement-form is its most visible face, but MPA also constructed specific ways of acting, configuring other modes of gathering. Among them figure the production of concepts in dialogue with the academia and transnational debates and the structuring of productive projects.

Keywords: Social movement; Peasants; Food sovereignty.

Este artigo descreve a trajetória do Movimento dos Pequenos Agricultores (MPA) entre 1996 e 2015 argumentando que, tendo sido criado a partir da forma-movimento - um modo específico de apresentar-se publicamente e uma linguagem capaz de fazer demandas ao Estado - o MPA, imediatamente, passou a alterar essa linguagem, associando-lhe novos elementos. Anos mais tarde, o MPA reorganizou sua pauta política e, ao fazê-lo, articulou-se a outros temas e práticas que, novamente, o transformaram. Algumas dessas práticas produziram efeitos desejados, passaram a ser reproduzidas em outras situações e nelas foram, novamente, transformadas. Mais do que o relato da trajetória do movimento entendido como um coletivo estável, o que aqui se sugere é uma leitura de que o próprio movimento vai se transformando ao longo do tempo, como efeito de suas formulações e de suas interações com outros grupos - Estado, academia e outros movimentos, nacionais e internacionais.

Nos anos 1990, emergiu no Brasil uma literatura preocupada em compreender o que eram e como funcionavam as ocupações de terras promovidas por movimentos e sindicatos de trabalhadores rurais. No geral, a literatura do período, como apontaram Sigaud, Ernandez e Rosa (2010), concentrava-se na formação dos movimentos (FERNANDES, 2010; NAVARRO, 2005) ou no que ocorria nos assentamentos da reforma agrária (MEDEIROS; LEITE, 1999; MARTINS, 2003). Ainda, outros textos, de escopo mais amplo, estiveram atentos ao processo de organização de trabalha- 
dores rurais com e sem terra inicialmente via sindicatos e, mais tarde, via movimentos (MEDEIROS, 1989).

O trabalho de Ligia Sigaud (2000), por sua vez, lançou luz sobre os acampamentos e apresentou padrões de organização que incluíam descrições de seu funcionamento, dos símbolos, das regras e do vocabulário próprio. Acampamentos eram promovidos e coordenados por grupos organizados, os movimentos (ou sindicatos, em alguns casos). A combinação de "aspectos modulares" que conformavam os acampamentos foi lida como "uma linguagem, um modo de fazer afirmações por meio de atos, destinada a fundar pretensões de legitimidade" (SIGAUD; ERNANDEZ; ROSA, 2010, p.12). Acampamentos ganharam repercussão à medida que essa linguagem foi compreendida por diferentes grupos - trabalhadores, proprietários rurais, políticos - e acolhida “como um pedido de redistribuição de terras" pelo Estado (ibid.).

A linha aberta por Sigaud desdobrou-se em outros trabalhos que se voltaram para o fenômeno da criação de diversos movimentos sociais rurais pelo país, com tamanhos e expressões políticas variadas, mas que mantinham o nome de movimentos e mimetizavam a ação do Movimento dos Trabalhadores Rurais Sem Terra (MST) - o que foi denominado forma-movimento. Afastando-se de explicações estruturais, Rosa (2011) leu a emergência dessas diversas organizações, muitas das quais de pequeno porte, a partir das possibilidades que abriam para o reconhecimento social dos indivíduos, que, criativamente, valeram-se de uma forma estabilizada de organização para mover "as velhas estruturas de significação social da sociedade brasileira por meio do estabelecimento de relações inéditas com o Estado e seus agentes" (ROSA, 2011, p.15). O Movimento dos Trabalhadores Rurais Sem Terra (MST) foi pioneiro em estabelecer essa nova linguagem de relação com o Estado, e a forma-movimento foi, em seguida, reproduzida por outros coletivos, rurais e urbanos, entre eles o Movimento dos Pequenos Agricultores, o MPA (ROSA, 2010).

Porém, acompanhando movimentos rurais no Brasil e na África por mais de uma década, aquele autor foi se dando conta de que nenhum dos coletivos que se associou à forma-movimento reproduziu-a exatamente da maneira como era performada pelo MST. A partir disso, em 2015, Rosa revisita o entendimento sobre sua forma-movimento. De "uma performance que havia se tornado para todos aqueles envolvidos em demandas por reforma agrária 
no Brasil" - inspirada nos escritos de Durkheim e Mauss sobre formas sociais e de Weber sobre legitimidade - reinterpretou o conceito, abrindo-o à possibilidade de transformação e reconhecendo que sua apropriação por outros movimentos e sindicatos além do MST foi marcada por inventividade, não apenas pela reprodução de uma forma pré-determinada:

Cada um deles leu o MST de acordo com a situação e conectou-o com outras "ferramentas", criando arranjos de acordo como que Law (2004) denomina "modos de compilar" (modes of gathering). De acordo com esse autor, todos os "modos de compilação" são parciais, circunstanciais e "conotam o processo de reunir, relacionar, escolher, encontrar, construir ou permitir fluxos" (LAW, 2004, p. 160). Tais modos, que podem facilmente ser considerados métodos de disputa (contention), são performativos no sentido que dão existência (enact) os temas que descrevem, trazendo-os, assim, dentro de certas fronteiras e limites. Em vez de simplesmente forçar pessoas a abraçar um modelo de disputa (contention) e negociação, a forma-movimento tornou-se um meio de transporte. Ela carregou ativistas pelo país e internacionalmente, de um movimento ao outro, levando agentes estatais para determinadas áreas rurais. Ademais, também permitiu a pesquisadores criar seus próprios conceitos, avançando e compreendendo a questão da terra muito além de um simples caso de pobreza e iniquidade em áreas rurais. (ROSA, 2015, p.53).

Duas ideias do texto acima são centrais para o presente artigo. Primeiro, a atenção ao trabalho dos atores sociais, de reunir, relacionar e construir fluxos. A percepção de que a ação passa pelo contínuo agenciamento ${ }^{1}$ de elementos diversos vem ganhando espaço na teoria social desde Deleuze e Guattari (1995) e vem sendo trazida para estudos sobre movimentos rurais e suas interações com o Estado (PENNA, 2018) bem como para a análise dos movimentos feministas (ALVAREZ, 2019). O processo de reunir elementos e permitir fluxos cria disputas e dá existência aos temas - e, diria Latour (2005), aos próprios coletivos.

Em segundo lugar, interessa a afirmação de que a forma-movimento tornou-se um "meio de transporte", na medida em que possibilitou aos ato-

1 Também traduzido como assemblage. Prefere-se aqui o termo usado na tradução de Mil Platôs (DELEUZE; GUATTARI, 1995), que enfatiza o ato de reunir os elementos diversos, não apenas a reunião, ou o que foi reunido. 
res que se engajassem em determinados processos ou atividades. Essa é, entendemos, uma característica central dos modos de compilar. Além dos contínuos agenciamentos, há estabilizações temporárias, isto é, há articulações entre elementos que, por terem os efeitos desejados pelos atores, são reproduzidas por eles em outras situações, criando o que temos, provisoriamente, denominado de quase-estabilizações, nos diálogos do Laboratório de Sociologia Não Exemplar da Universidade de Brasília (UnB). ${ }^{2}$ A forma-acampamento, a forma-movimento ou quaisquer outros agenciamentos quase-estabilizados podem ser lidos assim, como modos de articular elementos heterogêneos que são produzidos e reproduzidos pelos atores coletivos em busca de efeitos políticos. Por vezes, esses agenciamentos lhes permitem se engajar em novas disputas (e nesse sentido os transportam); nessas situações os agenciamentos são constantemente transformados na medida em que os colocam em relação com outros atores, temas, problemas e situações. No limite, modos de compilar são simultaneamente transportados pelos atores e os transportam, abrindo-lhes possibilidades de ação. Eles existem em constante tensão entre estabilidade e transformação.

O texto a seguir articula essas categorias analíticas para construir uma narrativa sobre o Movimento dos Pequenos Agricultores (MPA). Tendo partido da forma-movimento, sendo carregado por ela - que contribuiu para que suas ações ganhassem visibilidade pública - e carregando-a - para além dos debates estritamente sobre reforma agrária também para as disputas sobre política agrícola - o MPA construiu uma trajetória própria, em estreito diálogo com o MST tanto quanto com o novo sindicalismo e suas propostas de transformação do sindicalismo rural (PICOLOTTO, 2011)

O MPA recebeu atenção limitada da academia até recentemente. Foi estudado por Niemeyer (2014) e faz parte das análises de Picolotto (2011) que enfocavam a emergência da categoria agricultura familiar. Também foi objeto de artigos sobre ações específicas como moradia e projetos produtivos. Há, ainda, de publicações de seus militantes (GÖRGEN, 1998) e monografias e dissertações escritas por integrantes do movimento em cursos de especialização e mestrado (COSTA, 2014; CADONÁ, 2004). Além de fontes de informações e de sistematizações sobre a trajetória do MPA, trabalhos aca-

2 Sediado no Departamento de Sociologia da UnB e coordenado por Marcelo Carvalho Rosa. Mais informações em naoexemplar.com. 
dêmicos dos militantes evidenciam uma das diversas maneiras pelas quais esse movimento se relaciona com a academia, fornecem pistas sobre esforço de formação dos ativistas, apoiado pelo conjunto do movimento, e sobre a recente abertura de cursos de pós-graduação à inserção de ativistas rurais. Por fim, foram fontes de dados documentos produzidos pelo MPA (pautas nacionais, cartilhas e livretos) e textos assinados por lideranças do movimento para circulação interna ou divulgação. As fontes documentais foram complementadas com entrevistas de 15 militantes do MPA realizadas entre 2015 e 2016, a maioria deles ocupantes ou que já haviam ocupado funções de direção nacional ou estadual. Houve ainda uma visita de campo a cooperativas e projetos produtivos do movimento em Santa Catarina. Entrevistas e visitas foram realizadas no contexto da produção de tese de doutorado. A análise dos dados ateve-se a uma abordagem preocupada simultaneamente com a materialidade das práticas e aos objetos a elas associados, assim como aos discursos (LATOUR, 2005; LAW, 2004).

Revisitar a trajetória do MPA contribui para adensar as narrativas sobre o que são e o que fazem os movimentos sociais rurais, superando as exemplaridades que a própria literatura acadêmica criou a partir dos estudos mais atentos ao MST. As lentes aqui adotadas contribuem, sobretudo, para pensar sobre como se transformam os coletivos.

Neste artigo estão separados, analiticamente, dois modos de compilar da trajetória do MPA. O primeiro engloba de sua formação ao ano de 2002 e, ali, aponta-se como a forma-movimento é empregada e alterada; o segundo tem início em 2003 quando um novo governo, potencialmente aliado das pautas dos pequenos agricultores, chega ao poder com a eleição de Lula, e formula-se o Plano Camponês. Argumenta-se que o Plano Camponês transforma a maneira como o movimento age e se apresenta e, a partir dali, modifica-se o modo de compilar via iniciativas de produção de conhecimento, formulação de projetos produtivos e um intercâmbio contínuo com debates internacionais.

\section{Formação do MPA}

No Brasil da década de 1990, as forças políticas dos trabalhadores rurais passavam por transformações. Havia disputas no interior do sindicalismo. A Central Única dos Trabalhadores (CUT) havia criado um departamento rural nacional e o vinha estruturando nos estados, mas, posteriormente, re- 
formulou sua estratégia. Optou por uma composição política com os grupos e lideranças estabelecidos na Confederação Nacional dos Trabalhadores na Agricultura (Contag). Sindicalistas cutistas, então, passaram a fazer parte das chapas que concorreram às eleições da Confederação. Um dos resultados dessa aproximação foi a afiliação da Contag à CUT (PICOLOTTO, 2011; FAVARETTO, 2006). ${ }^{3}$ Simultaneamente, o Movimento dos Trabalhadores Rurais Sem Terra, MST, criado em 1984, transformava as formas de ação de trabalhadores rurais com acampamentos e ocupações de terra, renovando a gramática do diálogo entre essas populações e o poder público. Aliados como a Comissão Pastoral da Terra (CPT) também vinham contribuindo para reformulações nas maneiras de agir e de associar-se de pequenos proprietários e trabalhadores assalariados do campo. Valter Silva, um dos militantes do MPA que registra a trajetória do grupo, relaciona a origem do MPA a esses processos, assim como à seca que assolou o Sul do país em 1995:

[...] Houve uma reunião entre lideranças de diversos estados brasileiros que já apontava para a necessidade da organização de um Movimento Camponês, tendo em vista que o sistema sindical não estava mais respondendo a esta necessidade. Esta reunião teria acontecido um ano antes do Acampamento da Seca no Rio Grande do Sul, nos bastidores da Plenária Nacional do Departamento dos Rurais da CUT em 1995 em SP. Participaram lideranças dos sindicatos de trabalhadores rurais, CPT, MST e chegam à conclusão de que deveríamos criar um outro movimento. Cerca de um ano depois, com a seca no Sul esta conversa inicial se converte em luta concreta e na sequência em organização política que articula aqueles que estavam se sentindo órfãos e que agora tinham para onde convergir suas inquietações. (SILVA, 2011, p.8)

Nos relatos do próprio movimento, o "Acampamento da Seca”, em 1996, é o evento que desencadeia a criação do $\mathrm{MPA}^{5}$. A causa imediata do acampa-

3 Entre os sindicatos rurais, essa decisão de extinguir os Departamentos Rurais não foi unânime. Em Rondônia, um grupo descontente com a decisão foi um dos primeiros a participar da construção do MPA (SILVA, 2011).

4 Encontrei mais de uma versão sobre os municípios onde houve acampamentos: Sarandi, Júlio de Castilhos, Sananduva, Encruzilhada do Sul, e Três Passos (MPA, 2005). Notícia do Jornal Sem Terra, do MST, informa que a mobilização "acabou se espalhando por várias regióes e, a partir do dia 15/01, o trevo de Sarandi estava tomado pelas barracas de lona preta que chegaram a reunir 16 mil pessoas. Depois, mais acampamentos surgiram, em Frederico Westphalen, Palmeira das Missões, Lagoa Vermelha, Erechim, Chapecó, São Miguel do Oeste e Concórdia” (MST, 1996).

5 Niemeyer (2014) chama esse acampamento de "mito de origem" do MPA. 
mento foi a perda das lavouras de feijão e milho devido à seca. Participaram de sua criação agricultores em grave situação econômica, que não viam o êxodo rural como solução, em um momento de desvalorização dos produtos agrícolas que ocorreu no início do Plano Real ${ }^{6}$ e de altas taxas de desemprego nas cidades (COSTA, 2014). Relatos variam entre a presença de 15 a 30 mil pessoas.

Apesar da gravidade da situação e da disposição dos agricultores e de alguns sindicatos de trabalhadores rurais (STRs) para a mobilização, a Federação dos Trabalhadores na Agricultura do Rio Grande do Sul (Fetag-RS) recua e tenta adiar protestos já marcados, preferindo estratégias de negociação; os dirigentes sindicais cutistas reagem e tomam a frente do processo, iniciando o acampamento (COSTA, 2014; NIEMEYER, 2014; SILVA, 2011). É interessante notar, aqui, não a ausência de conexões com sindicatos, mas os conflitos e a existência de associações com algumas vertentes sindicais.

De modo geral, o perfil dos agricultores familiares reunidos pela Fetag-RS é de famílias mais estabelecidas e não raro inseridas em cadeias agrícolas de produção. Ainda que isso não conte toda a história do sindicalismo rural no estado, ese perfil contribuiu para a percepção de pequenos proprietários sobre a necessidade de organização a partir de outras bases políticas e lançando mão de outras estratégias.

No Acampamento da Seca, as reivindicações eram por anistia das dívidas do custeio agrícola da safra 95/96, criação de linha de crédito subsidiado para recuperação da capacidade produtiva, liberação de sementes de milho para alimentação dos animais e anistia de sementes concedidas pelo governo do Estado. ${ }^{7}$ A mobilização conseguiu uma "linha de crédito para auxiliar os pequenos agricultores, chamada de 'cheque- seca', no valor de R \$ 400,00” (CADONÁ, 2004).

Além do acampamento, houve episódios de fechamento da BR-386 e, frente à negativa de negociação do então governador do RS, os agricultores foram a Porto Alegre e ocuparam a Delegacia Regional do Ministério da Fazenda, onde enfrentaram repressão. O governo Federal respondeu liberando

6 Soja e milho foram vendidos quase pela metade do preço anterior ao real, segundo o Jornal Sem Terra (MST, 1996).

7 As pautas do MPA aqui citadas estão disponíveis em Valter Israel da Silva (2011) e sintetizadas em Maria José da Costa (2014). Agradeço a Silva pela disponibilização do documento, não publicado, que reúne depoimentos e materiais produzidos pelo MPA e vem sendo usado como base para pesquisadoras. Agradeço, igualmente, a Marciano Silva pela disponibilização de outros trabalhos sobre o MPA. 
recursos com juros de $12 \%$ ao ano. Agricultores recusaram a taxa de juros, e a federação de prefeitos e governo do RS assumiram, cada um, 3\% dos juros do financiamento (MST, 1996).

A linha de crédito solicitada seria semelhante à do Programa de Crédito Especial da Reforma Agrária (Procera) - havia, portanto, um conjunto de demandas por crédito no período. O tema, que estava também nas pautas do MST e da Contag, criava tensões com pequenos agricultores não assentados. Meses depois, em julho de 1996, foi lançado o Programa Nacional de Apoio à Agricultura Familiar (Pronaf). Porém, sem se sentir atendidos com as condições do Pronaf, os pequenos agricultores do Sul voltam a mobilizar-se desde o início de 1997 por "crédito subsidiado, seguro agrícola e fim da política de exclusão dos pequenos produtores” (COSTA, 2014, p. 63). Em setembro de 1997, agricultores levaram suas ferramentas a protesto, que ficou conhecido como Ferramentaço. Dias depois, 11 militantes deram início a uma greve de fome que durou até dois de outubro e foi planejada para coincidir com a vinda do Papa ao Brasil - sinal inequívoco da proximidade do grupo com setores da Igreja Católica. Em audiências em Brasília com o Ministério da Fazenda, o grupo obteve crédito subsidiado por meio da criação de uma linha especial do Pronaf, apelidada Pronafinho, para financiamento de custeio com rebate (bônus de adimplência) de $\mathrm{R} \$ 200,00$, operacionalizada em 1998 (Ibid.). Nessas ações, pequenos produtores associam elementos à forma-movimento, carregando ferramentas, trazendo as greves de fome.

Em dezembro de 1996, realiza-se um encontro de agricultores de sete estados, que decidem "construir um Movimento Nacional de Luta dos Pequenos Agricultores" tendo como princípios "lutas de massa - organização de base - formação política, ideológica e técnica - bandeiras simples, claras e objetivas.” (GÖRGEN, 1998, p. 63 apud SILVA, 2011, p. 13). Em julho de 1998, um segundo encontro reúne militantes do RS, ES, RO e MG e define formato e características do movimento ${ }^{8}$. Dali, o MPA apresenta uma pauta

8 Seria interessante trabalhar melhor a construção do movimento em cada estado, inclusive para pluralizar a narrativa de início no Sul do país. A partir de relatos de militantes do MPA reunidos por Silva (2011), sabe-se que em Rondônia a oposição sindical vinculada ao DNTR/CUT, descontente com o fim dessa instância e sem concordar com a estratégia da CUT de ocupar a Contag, buscou articulação em nível nacional. O primeiro contato com as articulações em curso no Sul do país teria acontecido por meio de uma cartilha encaminhada pelo gabinete do deputado Adão Preto. Depois da reunião nacional, os sindicatos de Rondônia passaram a fazer parte do MPA e suas comissões de base em RO acabaram por transformar-se em grupos de base do movimento. No Espírito Santo, as 
nacional. Além das demandas por crédito e anistia de dívidas e sementes de 1996 e 1997, inclui seguro agrícola subsidiado e preços agrícolas que viabilizem a produção. A pauta começa a trazer elementos da visão de mundo do movimento, pois fala da "agricultura familiar" como base para a produção de alimentos para o povo brasileiro" e de um "Projeto Alternativo de Desenvolvimento para o Brasil" que garanta emprego, terra, moradia e educação. Os termos evidenciam a proximidade ao DNTR/CUT. O MPA posiciona-se contra a política econômica do governo, pede aumento do poder aquisitivo do povo e reforma agrária.

Em 1999, o movimento segue pressionando pela renegociação de dívidas relativas a financiamentos para agricultura com ocupação de agências bancárias e bloqueios de rodovias. Em maio de 2000, é realizado o $1^{\circ}$ Encontro Nacional do MPA na cidade de Ronda Alta, RS, tendo como tema Organizar, produzir e alimentar. Reúnem-se 272 delegados (27 mulheres e 245 homens), 60 convidados, dos estados de RS, SC, RP, ES e RO (SILVA, 2011).

Moradia foi mencionada como condição para viver bem no campo desde a primeira pauta nacional do MPA, em 1998, como identificou Costa (2014). Mais tarde, tornou-se uma das mais evidentes conquistas do coletivo. Em 1998, o MPA foi "chamado de vendedor de ilusões porque defendia um crédito subsidiado para a construção de casas para as famílias camponesas” (COSTA, 2014, p.136). Naquele momento, pequenos agricultores não se encaixavam nas condições exigidas para programas habitacionais urbanos. Na pauta de 1999, seguia presente a demanda por crédito para moradia (SILVA, 2011). A partir de 2001, o MPA- que passa a ter um Setor de Habitação - estrutura um projeto piloto, o Programa Moradia Campo-

conexões também começaram nos encontros do DNTR e a primeira atividade dos grupos já sob o nome de MPA ocorreu em janeiro de 1998 e em maio foram realizadas ações públicas, como ocupações de bancos na luta por crédito do Pronaf. No Paraná, os primeiros contatos com militantes do Rio Grande do Sul, no sentido de estruturar o novo movimento, aconteceram em 1997. Em 2000, o MPA realiza sua primeira mobilização no estado, usando uma trilhadeira quebrada como símbolo das dificuldades enfrentadas para a produção de alimentos (CADONÁ, 2004). Em Sergipe, o MPA estruturou-se em 1999, no Semiárido e no Noroeste do estado (SANTOS E CONCEIÇÃO, 2013)

9 Niemeyer (2014) relaciona o uso inicial do termo "pequeno agricultor" com os debates promovidos pelo governo Federal no contexto da criação do Mercosul, ao tempo que "agricultor familiar" foi o termo que emergiu em meados na década de 1990 em meio aos debates por crédito diferenciado e foi adotado pela Contag (NIEMEYER, 2014, p. 193). Como veremos a seguir, após 2003 o MPA passa a trabalhar com o termo "camponês". Para debates teóricos sobre o sentido e o uso dos termos no Brasil, ver Neves, 2005; Picolotto, 2007. 
nesa $^{10}$, no RS, que então iniciava uma política estadual para a área. Foram construídas 2032 casas com mão-de-obra dos militantes e acesso a financiamento público (CARLOTO; ATIYEL, 2014). Pressionado por grupos como o MPA e a Fetraf-Sul, o governo Federal cria em 2003 o Programa Nacional de Habitação Rural, que depois passa a integrar o Programa Minha Casa Minha Vida (BOLTER, 2013). Até 2011, o MPA, por meio de cooperativas, envolveu-se na construção de 10.218 casas, em nove estados (CARLOTO; ATIYEL, 2014).

No início de 2001, durante o $1^{\circ}$ Fórum Social Mundial, o MPA participa das atividades da Via Campesina (DESMARAIS, 2013). Ali, tem papel proeminente na ocupação da área de experimentos da transnacional Monsanto, fabricante de agrotóxicos e sementes terminator e de soja transgênica, considerada "símbolo do projeto das elites para a agricultura"11 (MST, 2001). Já em 2001, a pauta nacional do movimento inclui a rejeição a sementes transgênicas e o conceito de soberania alimentar - uma das principais bandeiras de luta da Via Campesina, que entra nas formulações da rede transnacional em 1996. O MPA conecta o termo que tem origem na Via Campesina com as demandas ao governo nacional: "exigir do governo um amplo programa de estímulo à produção que garanta a Soberania Alimentar do Povo Brasileiro". Nesse período, intensifica-se a demanda de "defesa da agricultura familiar" com demanda de "uso de instrumentos legais internacionais para proteção", pois havia preocupação com a entrada de produtos subsidiados e demandas por compensação, regras sanitárias e aumento de tarifas (MPA, 2001, apud SILVA, 2011).

Quando entrou na cena pública brasileira, o MPA ficou conhecido como um movimento de demanda por crédito (ROSA, 2010). De fato, crédito foi tema onipresente nas pautas apresentadas pelo movimento ao governo Federal - em 11 delas, entre 1996 e 2013, só esteve ausente na de 2012. Porém, desde os primeiros anos, muitos outros temas estiveram presentes. Como

10 O Programa envolve a Caixa Econômica Federal, Secretaria de Habitação do RS, Agência Gaúcha de Fomento e Cooperativa de Crédito Rural Horizontes Novos de Sarandi - RS, e contando com recursos do Orçamento da União - Programa de Subsídio para Habitação de Interesse Social e do FGTS.

11 De acordo com o militante do MPA Marciano Silva (entrevista à autora, fev. 2015), o Fórum Social Mundial foi o momento de aproximação do MPA com a Via Campesina. Niemeyer (2014) afirma que o movimento se filiou à Via em 1998. No $2^{\circ}$ Fórum, em 2002, o MPA esteve no acampamento Internacional da Via Campesina, que tratou de temas como Reforma Agrária, Água, Soberania Alimentar, transgênicos, socialismo e dívida externa. 
vimos, entre 1996 e 2003, destacam-se questões relativas a dívidas e crédito e, a partir de 1998, o tema da habitação. Nas pautas do movimento no período figuram também seguro agrícola, reforma agrária, saúde, previdência, controle de preços e, inclusive, menções à agricultura ecológica, alimentos saudáveis e mudança do modelo tecnológico, ao lado das questões internacionais já mencionadas. A menção a sementes também começava a ganhar destaque, com preocupações em torno de anistia das sementes cedidas pelo poder público, após a seca, em 1998, mas também com o apoio à Campanha Brasil Livre de Transgênicos, em 2002. Em síntese, no início dos anos 2000, o MPA podia ser entendido como um movimento que articulava esse conjunto de temas e de ações a eles vinculadas e que, tendo se valido da forma-movimento para se estruturar, rapidamente agregou outros elementos às suas práticas, transformando-as.

\section{A construção do Plano Camponês}

Em fevereiro de 2003, o MPA realizou seu $2^{\circ}$ Encontro Nacional, em Ouro Preto do Oeste, RO. Ali, começava a ser construído, pelo conjunto do movimento, o Plano Camponês, pensado como uma proposta para a organização do campesinato e para o desenvolvimento do país (COSTA, 2014, p.92). O Plano sistematiza questões já abordadas pelo MPA e passa a organizar suas atividades em dois pilares: 1) condições para viver bem no campo e 2) condições para produzir. É dividido entre os itens produção, educação/formação, vida de qualidade, comunidade camponesa, soberania e contradições. Traz uma mudança relevante no discurso do MPA que é a identificação não mais como pequenos agricultores ou agricultores familiares, mas como "camponeses", o que, no entender do grupo, refere-se à possibilidade de continuar produzindo comida sem, necessariamente, integrar-se subordinadamente ao modelo capitalista. A agricultura camponesa diferencia-se da agricultura familiar justamente por não pretender integração subordinada ao modelo capitalista. Na esteira dessa mudança, o MPA passou a discutir o que significa ser camponês e camponesa no Brasil, em diálogo com a Via Campesina e com pesquisadores da área (GUZMÁN E MOLINA, 2005; CARVALHO, MOTTA, ZARTH, 2008).

Vinculados ao Plano Camponês, estão um conjunto de conceitos que passaram a orientar a atuação do movimento, cunhados pelo MPA e seus apoia- 
dores e parceiros, ou adaptados por seus militantes, e em constante debate e transformação. Ali está a soberania alimentar da Via Campesina, mas também soberanias energética, genética e hídrica - desdobramentos originais do conceito. Ali são associados temas como alimergia, sistemas camponeses de produção, agroecologia, terra e território, serviços socioambientais camponeses e cultura camponesa (para detalhes de cada um, ver MPA, 2015).

O argumento, aqui, é que a marca do MPA passa por articular esses temas e a partir deles produzir disputas políticas, em geral partindo de esforços de formulação conceitual, articulando elementos de debates nacionais e internacionais e promovendo iniciativas produtivas. A reunião dessas práticas sobre diferentes temas é, parece-me, algo que singulariza o MPA a partir dos anos 2000, sendo um modo de compilar que é transportado pelo movimento e o transporta a diversas outras disputas e locais. Não é possível, neste texto, dar conta das diversas situações em que esse modo de reunir coisas se performatiza, mas apontar essa articulação em algumas delas.

Em 2003, ativistas brasileiros encararam uma mudança conjuntural relevante. Luiz Inácio Lula da Silva assumia a presidência da República. A chegada do PT, antigo aliado das lutas políticas, ao governo Federal, e o lançamento do programa Fome Zero, aumentaram as expectativas sobre a melhoria da vida no campo, reforma agrária e crédito. A construção do Plano Camponês esteve, evidentemente, conectada a essas expectativas, que serviram como estímulo para repensar as pautas do movimento. Porém, nada disso veio automaticamente. Já em 2003, o MPA organizou cartilhas, debates com sua base, uma jornada de lutas, e procurou se posicionar "na condição de produtor de alimentos para dar respostas às demandas do programa fome zero". Além disso, apresentaram proposta de crédito sistêmico, que financiaria um conjunto de atividades e que, argumentavam, seria mais bem adaptado às pequenas propriedades camponesas. As propostas, porém, foram rejeitadas pelos interlocutores no governo Federal, o que levou o MPA a começar "um estudo mais aprofundado sobre o tema". ${ }^{12}$.

Os estudos sobre o tema tiveram como resultado o livro O Campesinato no Século XXI, coordenado por Horácio de Martins de Carvalho, a convite do MPA (CARVALHO, 2005). O autor articulou cerca de 70 intelectuais e pesquisadores e os textos reunidos foram avaliados e debatidos pelo movi-

12 Valter Israel da Silva, militante do MPA, entrevista à autora, fev.2015. 
mento. Alguns deles passaram a balizar o trabalho do MPA. Pouco depois, iniciou-se a preparação da coleção História Social do Campesinato Brasileiro, que terminou sendo composta por nove livros em cinco tomos e publicada pela editora da Universidade Estadual Paulista (Unesp) e pelo Núcleo de Estudos Agrários e Desenvolvimento Rural (Nead) do Ministério do Desenvolvimento Agrário (CARVALHO, MOTTA, ZARTH, 2008). Em 2013, o livro Mulheres Camponesas - trabalho produtivo e engajamentos políticos foi organizado por Delma Pessanha Neves e Leonilde Servolo de Medeiros (NEVES; MEDEIROS, 2013).

De forma geral, a construção do Plano desencadeou debates com intelectuais e no interior do MPA, desde a coordenação nacional até seus grupos de base. No relato de Silva: "Entramos em um processo de estudos, reflexões, pesquisas apoiadas por intelectuais e construção de conceitos e de propostas para políticas públicas. Este conjunto de argumentos, conceitos e propostas é o que chamamos de Plano Camponês". ${ }^{13}$ A profusão de publicações embasa a afirmação do cuidado do MPA com a formulação de conceitos e com o diálogo com a academia.

O trabalho da liderança Maria José Costa (2014) permite entrever como algumas das discussões inauguradas em 2003 estendem-se pelos anos seguintes, enfatizando o sentido de ruptura na adoção da identidade camponesa e a continuidade das demandas por políticas públicas, com cuja construção interagem, seja por meio de debates, seja por meio de protestos e mobilizações:

Foi neste ano [2003] que o MPA apresentou a pauta de um Crédito de Reestruturação da Agricultura Camponesa, o que levou a grandes disputas com o governo que dava continuidade à implantação do projeto da Agricultura Familiar. A proposta do crédito de reestruturação da Agricultura Camponesa era bombástica, pois ela por si só representava uma negação das políticas públicas propostas pelo governo para a agricultura camponesa e uma negação da identidade de agricultor familiar que tentavam nos impor.

No ano de 2008, portanto 5 anos mais tarde, o governo lançou o PRONAF Sistêmico, que respondia em parte a esta demanda e depois, com a crise alimentar virou o PRONAF Mais Alimento. (COSTA, 2014, p. 140).

13 Valter Israel da Silva, militante do MPA, entrevista à autora, fev. 2016. 
A partir de 2003, então, o MPA mantém o conjunto de temas com os quais já trabalhava e incorpora novos itens em suas pautas nacionais, tais como agroecologia, agroindústria, energia, regras sanitárias, serviços ambientais, acesso à internet, juventude e condições para sua permanência no campo, agrotóxicos (tema no qual a atuação das mulheres foi determinante). Também fazem referência a diversas políticas públicas como o Programa de Alimentação Escolar e o Programa de Alimentação Institucional, Programa Fome Zero, Luz Para Todos. Um tema de questionamento constante é o da educação - a partir de 2012, uma pauta recorrente é a crítica à política de fechamento de escolas do campo. A Reforma Agrária, nesse período, volta a figurar entre os temas, ao lado de demandas por mudanças na estrutura fundiária do país.

Foge ao escopo deste texto uma avaliação pormenorizada da relação do MPA com o governo Lula. Esse movimento não se afasta do padrão de interação identificado por Abers, Serafim e Tatagiba (2014), mas creio ser importante ressaltar que sua leitura das possibilidades e limites de um governo de esquerda é informada por uma análise de conjuntura que ressalta a dominação do capital sobre o Estado. Houve, nos governos petistas, convergências na criação de políticas públicas como o Programa de Aquisição de Alimentos (PAA) que multiplicou o mercado para pequenos agricultores, bem como um fluxo inédito de recursos para projetos produtivos. Houve, em paralelo, temas de embate, como a liberação de culturas transgênicas apesar dos questionamentos do Conselho Nacional de Segurança Alimentar (Consea), do qual o MPA fazia parte. Em linhas gerais, e tendo como base texto de dirigentes do MPA de 2015, pode-se afirmar que, após o fim da ditadura militar e como resposta à pressão dos movimentos sociais, o Estado brasileiro criou um conjunto de políticas públicas destinadas às populações do campo, e que o governo Lula as "ampliou e intensificou”:

Algumas delas são instrumentos importantes para a construção de políticas de Estado realmente estratégicas, como o seguro agrícola, a assistência técnica, a garantia de preços e a comercialização de alimentos e as compras governamentais. Mas todas enfrentam limites provocados pelo aumento das demandas e pela política de prioridades do Estado, na qual os camponeses constam subalternamente e, principalmente, em consequência das políticas macroeconômicas do Estado, capturadas pelos interesses do capital financeiro e do seu braço agroindustrial. (LEAL; GÖRGEN, 2015, p.87-88) 
Para além das pautas nacionais, nessa primeira década dos anos 2000, organiza-se o debate sobre educação, juventude e igualdade de gênero ${ }^{14}$. Coletivos de mulheres e de juventude organizam-se. Em 2003, o MPA realiza o $1^{\circ}$ Encontro Nacional sobre Relações de Gênero, Poder e Classe. A questão da presença das mulheres em cargos de coordenação entra definitivamente na pauta do movimento. As mulheres propuseram a Campanha Nacional Contra os Agrotóxicos, depois assumida por uma extensa rede de movimentos e organizações no Brasil e pela Via Campesina, o que aponta para sua capacidade de influenciar debates na rede transnacional de camponeses e antecipa o aprofundamento de sua influência sobre concepções e enquadramentos do MPA - que em 2014 assumiu a coordenação da Via Campesina Brasil. ${ }^{15}$

É nesse momento também que o MPA articula um discurso próprio sobre produção para os camponeses e estabelece um conjunto de estruturas produtivas que, como já afirmei, é uma das particularidades da forma de agir do MPA.

\section{Projetos estruturantes: sistemas camponeses de produção, alimergia e agroindústrias}

Nos documentos do movimento, a produção agrícola vem associada à capacidade de os pequenos agricultores produzirem alimentos saudáveis e de qualidade, para garantir a alimentação e a soberania alimentar do povo brasileiro, em contraponto a uma agricultura capitalista descrita como contaminada por agrotóxicos, com impactos negativos sobre o ambiente e ameaçadora da sobrevivência do modo de vida camponês. No Plano Camponês, o desafio de produção de alimentos saudáveis depende de um "arranjo econômico que permita não só aos camponeses ampliar sua produção em bases cada vez mais agroecológicas, mas também controlar essa produção permitindo fazer esse alimento chegar nos pratos dos trabalhadores do Brasil todo." 16

14 O material preparatório para o 10. Congresso do MPA traz rica síntese dos debates sobre esses três temas (MPA, 2015). Juventude e gênero foram objetos de assembleia e de mesas de debate durante o Congresso.

15 Para mais informações sobre as conexões entre o MPA e a Via Campesina, ver Niemeyer (2014) e Carvalho (2018).

16 Depoimento de Marcelo Leal, agrônomo e militante do MPA, ao vídeo I Congresso Nacional do MPA, em 2015: O salto qualitativo na organicidade do MPA https:/www.youtube.com/ watch?v=B8wMQyC-s0c. 
Em 2007, o MPA realiza seu $1^{\circ}$ Seminário Nacional de Produção, com o nome de Estratégias para a implementação do Plano Camponês. Nele, discutem-se os Sistemas Camponeses de Produção que virão a orientar as práticas do coletivo - com base na diversificação e na agroecologia, mas em busca de ampliar as escalas de produção (SILVA, 2011, p.65). Mais tarde, chegam ao conceito de alimergia, que busca reunir alimentos, meio ambiente e energia. Trata-se segundo o MPA, de conceito que visa a articular agricultura, pecuária e floresta para desenvolver formatos produtivos que integrem de maneira sinérgica a produção de alimentos e de energia com preservação ambiental - os resíduos de um ciclo se tornam insumos para outro (MPA, 2013, p.57). A agroecologia se torna elemento central dessas propostas.

Cabe notar, aqui, como a soberania alimentar - e seu desdobramento em soberania energética - é novamente central para a formulação do movimento. Um termo originado em uma organização transnacional, a Via Campesina, passa a fazer parte do discurso nacional com tal importância que torna difícil manter uma separação explícita entre "nacional” e "transnacional”, ao menos no campo da circulação de ideias.

Os Sistemas Camponeses de Produção, por sua vez, tornam-se a "lógica produtiva" do movimento, contrapondo-se ao conceito de cadeia produtiva e definidos como:

um complexo arranjo de cultivos, árvores, animais e solo, que garantem a circulação de produtos e subprodutos entre si, de modo que aquele produto do cultivo que não é usado para consumo familiar e nem comercialização vira alimento dos animais que, por sua vez, produzem alimentos para a família, para o mercado, para o solo e para outros animais. Para que esse conjunto funcione é necessário um conjunto de pequenas agroindústrias caseiras como a farinheira, o engenho, o moinho, o pilão, o monjolo, a queijaria, os tachos para fazer doces, o forne forno e o fogão a lenha, entre outros. (MPA, 2013, p.43)

A partir desses conceitos, o MPA passou a atuar para organizar "projetos estruturantes" - projetos produtivos com o objetivo de promover a diversificação da produção e de criar agroindústrias, agregando valor e facilitando a permanência das famílias no campo sem que precisem subordinar-se ao modelo hegemônico de produção, nem focar em uma só cultura que os mantenham dependentes de empresas compradoras, e sem abrir mão de suas formas de vida e economia (o que associam à agricultura familiar). A alter- 
nativa apresentada pelo movimento é uma mistura entre a vida do camponês contemporâneo, seus desafios, as práticas alternativas ao modelo vigente - capitalista, de integração a grandes cadeias econômicas - e um vir a ser desejado, sintetizado na adoção de práticas produtivas camponesas que passam pela agroecologia. Esses já eram, como vimos, temas do MPA, mas sua articulação torna-se mais evidente a partir do Plano Camponês.

Os projetos ganham perfis específicos em cada estado ou região em que o movimento atua. Para citar alguns: no Piauí, desenvolvem experiência de agroindústria de suco. No Espírito Santo, buscando sair da monocultura cafeeira, o trabalho é da consolidação de mercados para venda de frutas e hortaliças agroecológicas. Em Rondônia, produtores de café, grãos e frutas passam a produzir também álcool - inicialmente para autoconsumo - açúcar mascavo, melado e outros subprodutos para manejo. ${ }^{17}$

Em Santa Catarina, a cooperativa Oestebio tem como proposta coordenar a produção de sementes crioulas pelos agricultores, distribuindo-as para os próprios camponeses e para comercialização ao poder público. Com isso, cria condições para o resgate, manutenção e multiplicação de sementes crioulas de milho, feijão, aveia, trigo, além de soja, que passam pela gigantesca Unidade de Beneficiamento de Sementes antes de ser distribuídas para BA, SE, SC, PR, RS, AL, PI, RO, ES, CE, RN, PE, MG e AC. Nos primeiros anos da década corrente, a OESTEBIO fortaleceu-se com o fornecimento de sementes para programas de compras públicas e manteve cooperações com a Embrapa e com a Universidade Federal de Santa Catarina, entre outras. Mais recentemente, a diminuição de recursos federais para tais programas vem transformando a intensidade do trabalho. Essa cooperativa vendeu sementes para a Venezuela, onde o MPA foi convidado a desenvolver um projeto de cooperação.

Em Frederico Westphalen, no Rio Grande do Sul, instalou-se em 2005 um grande projeto com foco na produção de biocombustíveis, realizado pela Cooperbio - Cooperativa Mista de Produção, Industrialização e Comercialização de Biocombustíveis do Brasil Ltda. A proposta respondeu ao Programa Nacional de Produção de Biodiesel (PNPB), incentivando sua produção a partir de diferentes fontes oleaginosas nas várias regiões do país, como alternativa sustentável aos combustíveis fósseis. Naquele momento, organi-

17 Marciano Toledo da Silva, militante do MPA, entrevista à autora, fev. 2016. 
zações da Via Campesina questionaram a política por reproduzir a lógica do agronegócio, incentivando a monocultura de conhecidos impactos sociais e ambientais, inclusive pela ênfase na produção de soja. O MPA engajou-se no questionamento, mas também buscou aproveitar o debate instalado para propor um modelo que combinaria “produção de alimentos e de energia com proteção ao meio ambiente, por meio de uma produção diversificada e consorciada" (CAMACHO, 2013, p.86). O tema foi controverso, gerou seminários e publicações na Via Campesina e alianças com setores sindicais da área, sobretudo petroleiros. Divergências sobre a produção de insumos para bioenergia pelos camponeses chegaram a causar uma cisma no próprio MPA, contribuindo para a saída de militantes do Goiás que, em 2008, criaram nova organização, o Movimento Camponês Popular (MCP). Insere-se nessas controvérsias o esforço do MPA em conceituar alimergia e realizar experiências produtivas integrando produção de energia em sistemas.

Criada com apoio do Ministério do Desenvolvimento Agrário e da Petrobrás, a Cooperbio, instalou micro destilarias capazes de produzir álcool de cana, açúcar, melado, cachaça, doces, vinhoto e álcool de milho. Cada destilaria serviria a um conjunto de famílias, que se organizaria autonomamente e poderiam agregar valor à produção, mantendo as práticas de diversas culturas nas propriedades. A cooperativa seria um centro local de cooperação contribuindo para formação, suporte, processamento e comércio (LEAL; GÖRGEN, 2015). A experiência despertou interesse de pesquisadores de diversas áreas (ORTIZ, 2007; CAVALETT, LEAL, RYDBERG, 2010; ODERICH, 2014). O projeto teve altos e baixos e o debate das cooperativas entre os movimentos e sindicatos é antigo, porém, importa aqui perceber como o MPA formula e implementa suas práticas que, mais uma vez, inserem-se nos debates sobre políticas agrícolas em diálogo com o poder público, pesquisadores e ativistas.

\section{Considerações finais}

Este texto reuniu elementos da trajetória do MPA, descrevendo transformações e permanências em suas pautas, discursos e na materialidade de suas práticas por mais de 20 anos. Dialogando com a forma-movimento, a descrição das páginas precedentes permite argumentar que aquele formato, que contribuiu para que o MPA emergisse na cena pública na década de 
1990 foi transformado por suas ferramentas e pequenas propriedades em busca de crédito e melhores condições de vida e produção, mas continua sendo empregado. Bonés, bandeiras, gestos, o hino, a participação em protestos e manifestações e, mais raramente, acampamentos estão presentes. Todos eles foram vistos no $1^{\circ}$ Congresso Nacional do Movimento, em 2015.

Porém, a existência pública do MPA atualmente agrega outros elementos - alguns já presentes nos primeiros anos. Agora rearticulados e com maior visibilidade estão o contínuo esforço de produzir conceitos em diálogo com a base e com pesquisadores e pesquisadoras, as conexões com os debates internacionais da Via Campesina e, novamente, a incorporação e reformulação de conceitos e categorias. Por fim, está a ênfase nos projetos produtivos que, espalhados pelo país, buscam conferir materialidade às propostas. O MPA e seus militantes vinculam ideias e estruturas de produção que, juntas, dão existência a um conjunto de performances que possibilitam a existência do movimento e prefiguram o mundo preconizado por ele (LAW, 2004).

Em termos teóricos, as categorias de agenciamentos e modos de compilar são ferramentas analíticas que temos empregado no intuito de descrever os movimentos não como coletivos fixos, mas como articulações de elementos que são transformados ao longo do tempo, em uma contínua tensão entre permanências e mudanças. Essas transformações são evidentemente influenciadas pelas interações com o poder público e outros atores, mas são vistas aqui a partir da perspectiva de como ocorrem no interior de um coletivo específico, na medida em que as interações com atores externos e as formulações internas vão continuamente transformando os elementos que são reunidos, agregados e colocados em fluxo pelos movimentos. Assim, mais do que uma determinação do cenário externo - seja do capitalismo ou das instituições políticas nacionais - a existência dos movimentos é resultado da interação entre a ação e os elementos externos. Este tipo de abordagem teórica busca, justamente, lentes capazes de se manterem atentas ao que se move nos movimentos.

\section{Referências}

ABERS, Rebecca; SERAFIM, Lizandra; TATAGIBA, Luciana (2004), "Repertórios de interação estado-sociedade em um estado heterogêneo: a experiência na Era Lula”. Dados, Rio de Janeiro, v. 57, n. 2, p. 325-357. 
ALVAREZ, Sonia (2019), "Feminismos en Movimiento, Feminismos en Protesta”. Revista Punto Género n ${ }^{0}$ 11. Junio, p.73-102.

BOLTER, Jairo (2013), Interfaces e cogestão nas políticas para agricultura familiar: uma análise do Programa Nacional de Habitação Rural. Tese de Doutorado (Programa de Pós-graduação em Desenvolvimento Rural). Universidade Federal do Rio Grande do Sul - Porto Alegre.

CADONÁ, Célio (2004), Movimento dos Pequenos Agricultores-MPA: o novo nasce nas estradas. Dissertação de Mestrado (Programa de Pós-Graduação em Educação). Universidade Regional do Noroeste do Estado do Rio Grande do Sul (Unijuí) - Ijuí (RS), 283p.

CAMACHO, Rodrigo (2013), "Soberania alimentar e energética: a proposição camponesa para uma nova relação sociedade/natureza”. Fórum Ambiental da Alta Paulista, v. 9, n. 10, p. 76-91, 2013.

CARLOTO, Andréa.; ATIYEL, Carima (2014) "Políticas sociais no meio rural: a conquista do programa nacional de habitação rural”. Anais do $6^{\circ}$. Seminário Nacional Estado e Políticas Públicas. Unioeste, 2014. ISSN: 2358-7563

CARVALHO, Horácio Martins (2005), O Campesinato no Século XXI Possibilidades e condicionantes para o desenvolvimento do campesinato no Brasil. Petrópolis: Vozes.

CARVALHO, Horácio Martins.; MOTTA, Márcia.; ZARTH, Paulo (coord.) (2008), “Apresentação à Coleção”. In: NEVES, Delma P.; SILVA, Maria A. (org.). Processos de constituição e reprodução do campesinato no Brasil, vol.1. São Paulo: Editora UNESP; Brasília: NEAD (Coleção História social do campesinato brasileiro).

CARVALHO, Priscila D. (2018), A produção do transnacional:compilações da agricultura familiar e camponesa na Contag e no MPA. Tese de Doutorado (Programa de Pós-graduação em Ciência Política). Universidade Federal de Minas Gerais - Belo Horizonte.

CAVALETT, Otavio; LEAL, Marcelo.; RYDBERG, Torbjörn (2010), “Avaliação energética de sistema camponês de produção de álcool, alimentos e serviços ambientais”. In: LEAL, Marcelo. Agricultura e mudanças climáticas. A contribuição dos sistemas camponeses de produção para uma agricultura sustentável. Palmeira das Missões: MPA.

COSTA, Maria José. (2014), Construção do Plano Camponês: experiências de políticas públicas de desenvolvimento para o campo brasileiro. Dissertação de Mestrado (Geografia). Universidade Estadual Paulista (Unesp) - Presidente Prudente.

DESMARAIS, Annete (2013), A Via Campesina. São Paulo: Cultura Acadêmica; Expressão Popular, 2013. 
DELEUZE, Gilles; GUATTARI, Felix (1995), Mil platôs. Capitalismo e Esquizofrenia, vol.2, São Paulo: Editora 34.

FAVARETO, Arilson (2006), "Agricultores, trabalhadores: os trinta anos do novo sindicalismo rural no Brasil.” Rev. bras. Ci. Soc. [online], vol.21, n.62, pp.27-44.

FERNANDES, Bernardo Mançano. (2010), "Formação e territorialização do MST no Brasil”. In: CARTER, Miguel (ed.). Combatendo a desigualdade social. O MST e a reforma agrária no Brasil. São Paulo: Ed. Unesp, p. 161197.

GÖRGEN, Sergio (1998), A resistência dos pequenos gigantes - A luta e a organização dos Pequenos Agricultores. Petrópolis: Vozes.

GUZMÁN, Eduardo. MOLINA, Manuel (2013), Sobre a evolução do conceito de campesinato. São Paulo: Expressão Popular.

LAW, John (2004), After Method. Mess in social science research. New York: Routledge.

LATOUR, Bruno (2005). Reassembling the Social. Oxford: Oxford University Press, 2005.

LEAL, Marcelo.; GÖRGEN, Sergio (2015), "Desafios da agricultura camponesa no século XXI”. In: STEFANO, Daniela; MENDONÇA, Maria Luiza. (Org.). Direitos Humanos no Brasil 2006: relatório da rede social de justiça e direitos humanos. São Paulo: Outras Expressões, pp. 87-96.

MARTINS, José de Souza (org.) (2003), Travessias. A vivência da Reforma Agrária nos Assentamentos. Porto Alegre, Editora da UFRGS.

MEDEIROS, Leonilde S. (1989), História dos movimentos sociais no campo. Rio de Janeiro: FASE.

MEDEIROS, Leonilde S. de; LEITE, Sérgio (org.) (1999), A Formação dos Assentamentos Rurais no Brasil. Porto Alegre/Rio de Janeiro, Ed. Universidade UFRGS; CPDA.

MOVIMENTO DOS PEQUENOS AGRICULTORES- MPA (2001), Pauta de lutas para o ano 2001.

MOVIMENTO DOS PEQUENOS AGRICULTORES - MPA (2005), Grupos de base: o alicerce do MPA.

MOVIMENTO DOS PEQUENOS AGRICULTORES - MPA (2013), Plano Camponês: construindo o novo caminho da roça IV. Plano Nacional de Ações para a Soberania Alimentar desde uma Perspectiva de Gênero. Brasília: MPA.

MOVIMENTO DOS PEQUENOS AGRICULTORES - MPA (2015), Caderno de estudos n.1 - I Congresso Nacional do MPA. Brasília: MPA. 
MOVIMENTO DOS TRABALHADORES RURAIS SEM TERRA - MST (1996), Pequenos agricultores do Sul lutam por política agrícola. Jornal Sem Terra, Ano XV, n 155, Janeiro-Fevereiro, p. 13.

MOVIMENTO DOS TRABALHADORES RURAIS SEM TERRA - MST (2001), Somente lutando outro mundo é possível. Jornal Sem Terra, Ano XIX, n 207, p.11, fevereiro. Disponível em: http://www.docvirt.com/docreader.net/ docreader.aspx?bib=HEMEROLT\&PagFis $=2985$. Acesso em: 01 de abril de 2020 .

NAVARRO, Zander (2005), "Mobilização sem emancipação: as luas socais dos sem-terra no Brasil”. In: SANTOS, Boaventura. Produzir para viver: os caminhos da produção não capitalista. Rio de Janeiro: Civilização Brasileira, pp.189-232.

NEVES, Delma. P.; MEDEIROS, Leonilde. S. (org.) (2013), Mulheres Camponesas - trabalho produtivo e engajamentos políticos. Niterói: Alternativa.

NEVES, Delma P. (2005), “Campesinato e reenquadramentos sociais: os agricultores familiares em cena”. Revista NERA, v. 8, n. 7, p. 68-93.

NIEMEYER, Carolina. B. (2014), Movimentos sociais como produtores de conhecimento: a Soberania Alimentar no Movimento de Pequenos Agricultores (MPA). Tese de Doutorado (Sociologia/Iesp). Universidade do Estado do Rio de Janeiro (UERJ) - Rio de Janeiro.

ODERICH, Edmundo (2014), Desempenho e potencial agroeconômico da produção de etanol em microdestilarias em pequenas propriedades na região nordeste do Rio Grande do Sul. Tese de Doutorado (Programa de Pós-graduação em Desenvolvimento Rural). Universidade Federal do Rio Grande do Sul - Porto Alegre.

ORTIZ, Lucia (coord.) (2007), "Despoluindo Incertezas. Impactos locais da expansão das monoculturas energéticas no Brasil e Replicabilidade de Modelos Sustentáveis de Produção e Uso de Biocombustíveis”. Relatório. Disponível em: http://www.mp.go.gov.br/nat_sucroalcooleiro/Documentos/ documentos_art/06.pdf. Acesso em 01 de abril de 2020.

PENNA, Camila (2018), "Gênese da relação de parceria entre Incra e movimentos sociais como modelo para implementação de políticas de reforma agrária”. Lua Nova [online], n.105, pp.115-148.

PICOLOTTO, Everton (2007), "Movimentos sociais rurais no sul do Brasil: novas identidades e novas dinâmicas”. Revista Ideas - Interfaces em Desenvolvimento, Agricultura e Sociedade, v. 1, n. 1, pp. 60-77.

PICOLOTTO, Everton (2011), As Mãos que Alimentam a Nação: agricultura familiar, sindicalismo e política. Tese de Doutorado. Programa de PósGraduação de Ciências Sociais em Desenvolvimento, Agricultura e Sociedade. Universidade Federal Rural do Rio de Janeiro - Rio de Janeiro. 
ROSA, Marcelo (2010), "Para além do MST: O impacto nos movimentos sociais brasileiros”. In: CARTER, Miguel (ed.). Combatendo a desigualdade social. O MST e a reforma agrária no Brasil. São Paulo: Ed. Unesp, p. 461-447.

ROSA, Marcelo (2011), O engenho dos movimentos sociais. Reforma agrária e significação social na zona canavieira de Pernambuco. Rio de Janeiro: Garamond.

ROSA, Marcelo (2015), "A journey with the Movimento dos Trabalhadores Rurais sem Terra (MST) across Brazil and on to South Africa”. Études Rurales, v. 196, p. 43-56.

SANTOS, Ricardo M.; CONCEIÇÃO, Alexandrina. L. (2013), O movimento dos pequenos agricultores - MPA e a soberania alimentar: outra perspectiva para o campo sergipano. Anais NPGEO 30 anos de contribuição à Geografia, Aracaju.

SIGAUD, Lygia (2000), “A forma acampamento. Notas a partir da versão Pernambucana”. Novos estudos CEBRAP, v. 58, p. 73-92.

SIGAUD, Lygia; ERNANDEZ, Marcelo; ROSA, Marcelo (2010). Ocupações e acampamentos. Rio de Janeiro: Garamond.

SILVA, Valter. I (2011). Histórico e Organicidade do MPA - 15 anos de história do Movimento dos Pequenos Agricultores. Mimeo.

Submetido em 12 de dezembro de 2019

Aprovado em 21 de fevereiro de 2020

\section{(cc) $\mathrm{BY}$}

Licenciado sob uma Licença Creative Commons Attribution 3.0 